\title{
Electrochemical and Quantum Chemical Studies of 5-Substituted Tetrazoles as Corrosion Inhibitors for Copper in Aerated $0.5 \mathrm{M} \mathrm{H}_{2} \mathrm{SO}_{4}$ Solution
}

\author{
Pengju Liu ${ }^{1}$, Xia Fang ${ }^{2}$, Yongming Tang ${ }^{1}$, Chunning Sun ${ }^{1}$, Cheng Yao ${ }^{1}$ \\ ${ }^{1}$ College of Science, Nanjing University of Technology, Nanjing, China; ${ }^{2}$ Department of Chemistry, Jiangsu Institute of Education, \\ Nanjing, China. \\ Email: yaochengnjut@126.com
}

Received May $16^{\text {th }}, 2011$; revised June $2^{\text {nd }}, 2011$; accepted June $9^{\text {th }}, 2011$.

\begin{abstract}
Two 5-substituted tetrazoles, 5-(2-thienyl)-1,2,3,4-tetrazole (2-THTT) and 5-(4-pyridyl)-1,2,3,4-tetrazole (4-PYTT), as copper corrosion inhibitors in aerated $0.5 \mathrm{M} \mathrm{H}_{2} \mathrm{SO}_{4}$ solution were studied by using potentiodynamic polarization, electrochemical impedance spectroscopy (EIS) and quantum chemical calculation. Polarization curves indicate that inhibition efficiencies of tetrazoles increase with increasing inhibitors concentration. The electrochemical results show that the inhibition efficiency of 2-THTT is higher than that of 4-PYTT. Inhibition efficiency of 2-THTT reached 98.9\% at very low concentrations $(0.25 \mathrm{mM})$ by EIS, which makes 2-THTT an efficient inhibitor in aerated $0.5 \mathrm{M} \mathrm{H}_{2} \mathrm{SO}_{4}$ solution. The adsorption of 5-substituted tetrazoles on copper surface obeys the Langmuir isotherm. All the computed quantum chemical parameters are found to correlate well with experimental inhibition efficiencies of inhibitors.
\end{abstract}

Keywords: Copper, Tetrazole, $\mathrm{H}_{2} \mathrm{SO}_{4}$, Corrosion, Inhibition

\section{Introduction}

As is known to all, using inhibitors is an important method of protecting materials from corrosion. Many heterocyclic compounds containing sulfur, phosphorus, nitrogen, and oxygen atoms are efficient inhibitors of corrosion for copper in acid media [1-7]. And there has been much interest in the development of tetrazole compounds as corrosion inhibitors. The inhibition efficiencies of 1,5-disubstitued 1,2,3,4-tetrazoles, in which the substituted groups include 1-phenyl-5-mercapto [8-13], 5-amino [8,10,13], 1-phenyl [8,10,13], 1-methyl-5-mercapto [8], 5-(3-Aminophenyl) [14], have been studied for copper in acidic media.

Recently, investigations of the relation between the efficiency and structural properties of inhibitor molecules have been taken by many experimental techniques and theoretical methods. Quantum chemistry calculations have been widely used to study the reaction mechanisms and to interpret the experimental results as well as to solve chemical ambiguities $[15,16]$. This is a powerful approach to investigate the mechanisms of reaction in the molecule, and its structure and electronic parameters can be obtained by quantum chemistry calculations $[17,18]$. Some quantum mechanical studies have successfully interpreted the relation between the corrosion efficiency and structural properties of inhibitor molecules [19-23].

The present work reports the inhibition of copper corrosion in aerated $0.5 \mathrm{M} \mathrm{H}_{2} \mathrm{SO}_{4}$ solution by 5-(2-thienyl)1,2,3,4-tetrazole (2-THTT) and 5-(4-pyridyl)-1,2,3,4-tetrazole (4-PYTT) (Figure 1). Potentiodynamic polarization, electrochemical impedance spectroscopy (EIS) and quantum chemical calculation were used. A perusal of literature reveals that 2-THTT and 4-PYTT have not been reported as corrosion inhibitor. Tetrazoles studied are expected to be good inhibitor for copper corrosion in $\mathrm{H}_{2} \mathrm{SO}_{4}$ solution because they are heterocyclic compound containing the tetrazole ring, in addition to the thienyl and pyridyl group.

\section{Experimental Method}

\subsection{Electrochemical Measurements}

The aggressive solution were prepared by dilution of concentrated $\mathrm{H}_{2} \mathrm{SO}_{4}$ (reagent-grade) with ultrapure water. Ultrapure water was produced by New Human UP 900 


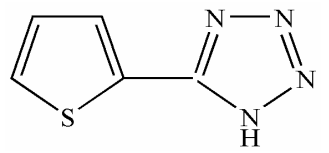

2-THTT

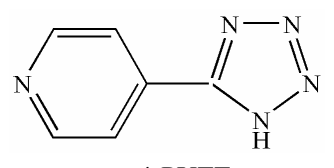

4-PYTT
Figure 1. Structures of 5-substituted tetrazoles.

(Human Corporation) Purified Water Systems. 2-THTT and 4-PYTT were synthesized by the method reported in the literature referenced [24].

A traditional three-electrode cell was used for electrochemical measurements. A platinum sheet electrode was used for the auxiliary electrode, and the reference electrode was a saturated calomel electrode (SCE) with a Luggin capillary. All potentials were measured with respect to the SCE. The working electrode was the "Gaoss Union" (a company) customized commercial products. And it, in the form of a rod cut from pure copper ( $99.99 \%$ purity, $\Phi=6 \mathrm{~mm}$ ) sheet, had a geometric area of $0.2827 \mathrm{~cm}^{2}$. Prior to each experiment, the electrode was ground with various grades of grit emery paper (up to 2000 grit), cleaned with absolute ethanol, thoroughly washed with ultrapure water and finally dried in dry air. All experiments were repeated three times at the desired temperature $\pm 1^{\circ} \mathrm{C}$.

Electrochemical experiments were carried out using a CHI 660C electrochemical workstation. Potentiodynamic polarization curves were recorded at a sweep rate of 1 $\mathrm{mV} / \mathrm{s}$. Electrochemical impedance spectroscopy (EIS) measurement were carried out at open-circuit potential (OCP). The $a c$ frequency range extends from $100 \mathrm{kHz}$ to $10 \mathrm{mHz}$ with a $5 \mathrm{mV}$ peak-to-peak sine wave as the excitation signal. Electrochemical data were obtained after $1 \mathrm{~h}$ of immersion with the working electrode at the rest potential, and all tests have been performed in non-deaerated solution under unstirred conditions. Electrochemical data were analyzed and fitted with ZSimpWin ver. 3.51.

\subsection{Computation of Quantum Chemical Parameters}

Quantum chemistry calculations were carried out by semiempirical PM3 method from the program package MOPAC2007. A full optimization of all geometrical variables without any symmetry constraint was performed at the Restricted-Hartree-Fock (RHF) level. Molecular structures were optimized to the gradient $<0.01$ in the vacuum phase.

\section{Results and Discussion}

\subsection{Polarization Curves}

Polarization curves of the copper electrode in aerated 0.5
$\mathrm{M} \mathrm{H}_{2} \mathrm{SO}_{4}$ solution at $30^{\circ} \mathrm{C}$ in the absence and presence of 5 -substituted tetrazoles are shown in Figure 2. Electrochemical parameters, i.e., corrosion potential $\left(E_{c o r r}\right)$, cathodic and anodic Tafel slope $\left(b_{c}\right.$ and $\left.b_{a}\right)$ and corrosion current density $\left(I_{\text {corr }}\right)$, obtained by extrapolation of the Tafel lines, are presented in Table 1. The inhibition efficiencies $(E \%)$ of the tetrazole compounds in $0.5 \mathrm{M}$ $\mathrm{H}_{2} \mathrm{SO}_{4}$ are also given in Table 1, and it $(E \%)$ was calculated according to the relation [25] :

$$
E(\%)=\frac{I_{\text {corr }}^{0}-I_{\text {corr }}}{I_{\text {corr }}^{0}} \times 100
$$

where $I_{\text {corr }}^{0}$ and $I_{\text {corr }}$ are the corrosion current densities obtained from uninhibited and inhibited solution, respecttively.

As can been seen from Figure 2, both anodic and cathodic reactions of corrosion process were significantly inhibited while the tetrazole derivatives were added to the acid solution. The addition of the compounds studied decreased the current densities in a large domain anodic and cathodic of potential. In literature, it has been reported that $[26,27]$ if the displacement in $\left.E_{\text {corr }} 1\right)$ is $>85$ $\mathrm{mV}$ with respect to $E_{\text {corr }}$, the inhibitor can be seen as a cathodic or anodic type and 2) if the displacement in $E_{\text {corr }}$ is $<85 \mathrm{mV}$, the inhibitor can be seen as mixed type. In our study, the maximum displacement in $E_{\text {corr }}$ value is 17 $\mathrm{mV}$ towards anodic region, which indicates that all tetrazoles studied are mixed-type inhibitors [28]. In naturally aerated acidic medium, copper corrosion involves a simultaneous anodic dissolution and cathodic oxygen reduction reaction (ORR) process $[29,30]$. The increase in inhibition efficiency with increasing inhibitor concentration may be attributed to the formation of a barrier film, which prevents the attack of acid on the metal surface [31]. From Figure 2, it also can be seen that the anodic curves in Figure 2(a) and Figure 2(b) look different. Those in Figure 2(a) show a step in the anodic curve between about 0 and $0.08 \mathrm{~V}$ (vs SCE), and this in Figure 2(b) do not show this. The two inhibitors have a different effect on the anodic reaction. It may be caused by a stronger effect of adsorption of 2-THTT on copper surface than 4-PYTT. This show that 2-THTT may show better corrosion inhibition than 4-PYTT in the aerated $0.5 \mathrm{M} \mathrm{H}_{2} \mathrm{SO}_{4}$ solution.

It can be observed from Table 1 that the Icorr values decrease considerably in the presence of 2-THTT and 4-PYTT and the Icorr values have a trend to decrease with the increasing inhibitor concentration. Correspondingly, inhibition efficiencies $(E \%)$ values increase with the increasing inhibitor concentration and then reach a maximum value at $0.25 \mathrm{mM}$ in the both cases of inhibittors. Additionally, it is also evident that 2-THTT presents 
Table 1. Electrochemical parameters for the corrosion of copper in $0.5 \mathrm{M} \mathrm{H}_{2} \mathrm{SO}_{4}$ containing different concentrations of inhibitors at $30^{\circ} \mathrm{C}$.

\begin{tabular}{|c|c|c|c|c|c|c|}
\hline Inhabitor & $\mathrm{C}_{\mathrm{inh}}(\mathrm{mM})$ & $E_{\text {corr }}(\mathrm{mV})$ & $I_{\text {corr }}\left(\mu \mathrm{A} \cdot \mathrm{cm}^{-2}\right)$ & $b_{c}\left(\mathrm{mV} \cdot \mathrm{dec}^{-1}\right)$ & $b_{a}\left(\mathrm{mV} \cdot \mathrm{dec}^{-1}\right)$ & $I E(\%)$ \\
\hline \multirow[t]{3}{*}{ Blank } & - & -24 & 69.14 & -614.25 & 49.75 & - \\
\hline & 0.05 & -9 & 9.46 & -456.62 & 52.65 & 86.3 \\
\hline & 0.10 & -10 & 8.18 & -474.16 & 75.35 & 88.2 \\
\hline \multirow[t]{5}{*}{ 2-ТHTT } & 0.15 & -7 & 5.98 & -352.11 & 66.13 & 91.4 \\
\hline & 0.20 & -7 & 5.64 & -378.64 & 72.20 & 91.9 \\
\hline & 0.25 & -10 & 4.80 & -343.05 & 66.53 & 93.1 \\
\hline & 0.05 & -17 & 12.70 & -401.61 & 41.16 & 81.6 \\
\hline & 0.10 & -20 & 10.78 & -425.71 & 44.13 & 84.4 \\
\hline \multirow[t]{3}{*}{ 4-PYTT } & 0.15 & -21 & 9.02 & -392.93 & 45.10 & 87.0 \\
\hline & 0.20 & -29 & 6.67 & -394.48 & 44.77 & 90.4 \\
\hline & 0.25 & -29 & 5.11 & -368.87 & 45.84 & 92.6 \\
\hline
\end{tabular}
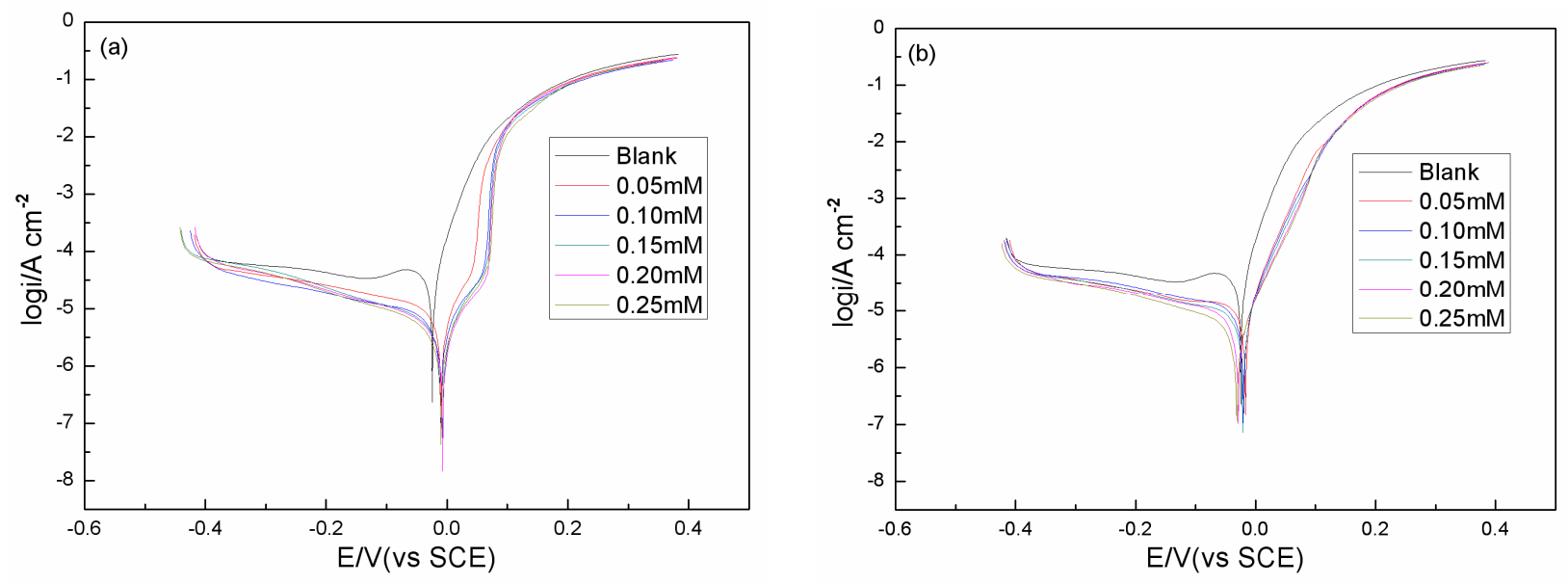

Figure 2. Potentiodynamic polarization curves for copper in the absence and presence of (a) 2-THTT and (b) 4-PYTT.

slightly better performance than 4-PYTT, which can be correlated to the difference in the heteroatom of the substituted heterocyclic between the two molecules.

\subsection{Effect of Temperature}

Some information about adsorption mechanism of the inhibitor can be obtained from the activation energy values, and the activation energy of corrosion process can be obtained by investigating the influence of temperature on corrosion inhibition. Effect of temperature was studied by polarization tests in the absence and presence of $0.1 \mathrm{mM}$ of 2-THTT and 4-PYTT, as shown in Figure 3. Corresponding electrochemical data are given in Table 2.

As seen from Figure 3 and Table 2, the corrosion current density increases with the increasing temperature, both in uninhibited and inhibited solutions. In the solution containing 2-THTT, slight changes in values of inhibition efficiencies are observed in the range of temperature studied. Thus the compound can be regarded as the temperature-independent inhibitors. However, from Table 2, it is clear that the efficiency of 4-PYTT decreases with the increasing temperature. Therefore, 4PYTT should be assigned as temperature-dependent inhibitor.

In order to calculate the activation energy of the corrosion process, Arrhenius equation was used [32]:

$$
I_{\text {corr }}=k \exp \left(-\frac{E_{a}}{R T}\right)
$$

where $k$ is the pre-exponential factor, $E_{a}$ is the apparent 
Table 2. Electrochemical parameters and activation parameters of the corrosion of coppr in $0.5 \mathrm{M} \mathrm{H}_{2} \mathrm{SO}_{4}$ solution in the absence and presence of $0.1 \mathrm{mM}$ inhibitor.

\begin{tabular}{|c|c|c|c|c|c|}
\hline Inhibitor & $\operatorname{Tmp}\left({ }^{\circ} \mathrm{C}\right)$ & $E_{\text {corr }}(\mathrm{mV})$ & $I_{\text {corr }}\left(\mu \mathrm{A} \cdot \mathrm{cm}^{-2}\right)$ & $I E(\%)$ & $\mathrm{E}_{\mathrm{a}}\left(\mathrm{kJ} \cdot \mathrm{mol}^{-1}\right)$ \\
\hline \multirow{4}{*}{ Blank } & 25 & -28 & 59.42 & - & \multirow{4}{*}{37.73} \\
\hline & 30 & -24 & 69.14 & - & \\
\hline & 35 & -21 & 97.44 & - & \\
\hline & 40 & -23 & 119.22 & - & \\
\hline \multirow{4}{*}{ 2-THTT } & 25 & -13 & 5.98 & 89.9 & \multirow{4}{*}{46.32} \\
\hline & 30 & -10 & 8.18 & 88.2 & \\
\hline & 35 & -7 & 11.10 & 88.6 & \\
\hline & 40 & -12 & 14.60 & 87.8 & \\
\hline \multirow{4}{*}{ 4-PYTT } & 25 & -23 & 7.23 & 87.8 & \multirow{4}{*}{66.28} \\
\hline & 30 & -20 & 10.78 & 84.4 & \\
\hline & 35 & -16 & 17.01 & 82.5 & \\
\hline & 40 & -14 & 25.78 & 78.4 & \\
\hline
\end{tabular}
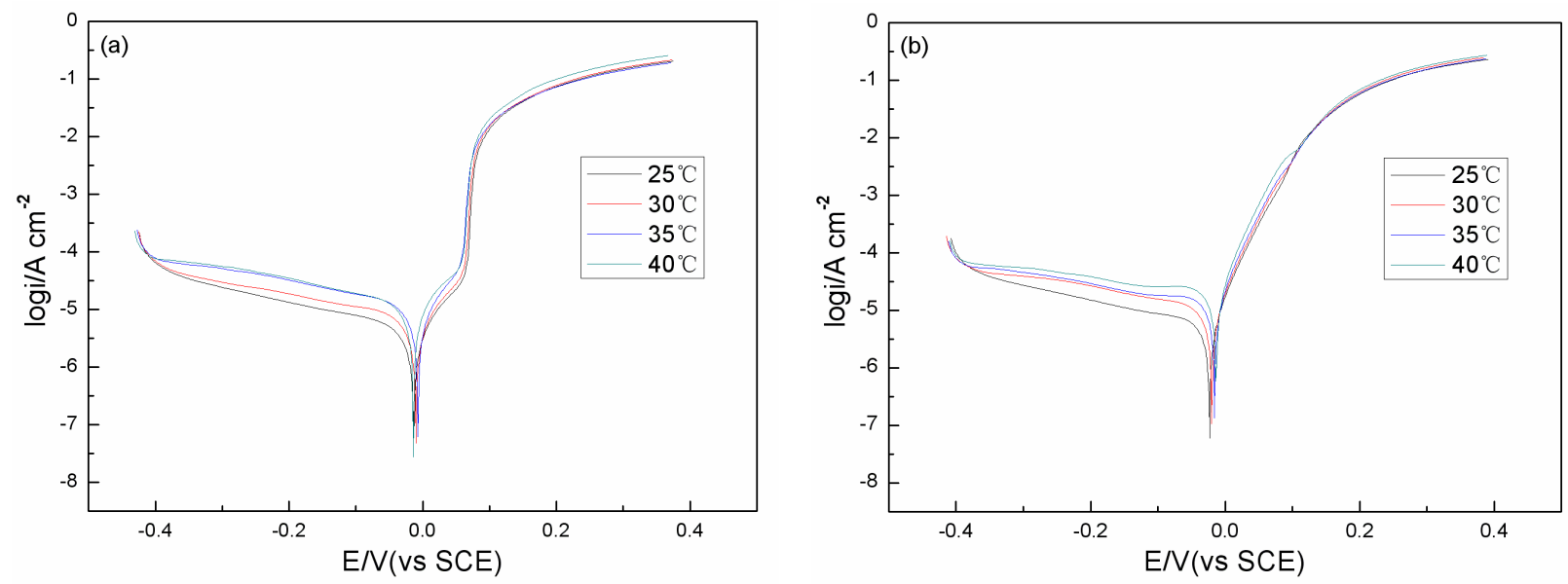

Figure 3. Effect of temperature on the cathodic and anodic responses for copper in $0.5 \mathrm{M} \mathrm{H}_{2} \mathrm{SO}_{4}+0.1 \mathrm{mM}$ of (a) 2-THTT and (b) 4-PYTT.

activation energy of the corrosion process, $R$ is the gas constant and $T$ is the absolute temperature. Figure 4 shows Arrhenius plots of the logarithm of the current density vs $1 / T$ for copper in the corrosive medium with and without addition of $0.1 \mathrm{mM}$ of 2-THTT and 4-PYTT. Straight lines are obtained with a slope of $\left(-E_{a} / R\right)$. Activation parameters obtained from this graph are given in Table 2.

It is well known that unchanged or lower values of $E_{a}$ in inhibited systems compared to the blank indicate the chemisorption mechanism, while higher values of $E_{a}$ suggest the physical adsorption mechanism [33-37]. From Table 2, it is observed that the values of $E_{a}$ ob- tained in presence of 2-THTT and 4-PYTT increase significantly compared to the values of $E_{a}$ in inhibitor-free solution. This indicates a physisorption mechanism of the two 5-substituted tetrazoles on copper surface that occurs in the first stage [38-40]. The increase in activation energy can be attributed to an appreciable decrease in the adsorption of the inhibitor on the copper surface with the increase in temperature [39,41-43].

\subsection{Electrochemical Impedance Spectroscope (EIS)}

The corrosion of copper in aerated $0.5 \mathrm{M} \mathrm{H}_{2} \mathrm{SO}_{4}$ solution in the presence 2-THTT and 4-PYTT was investigated by 


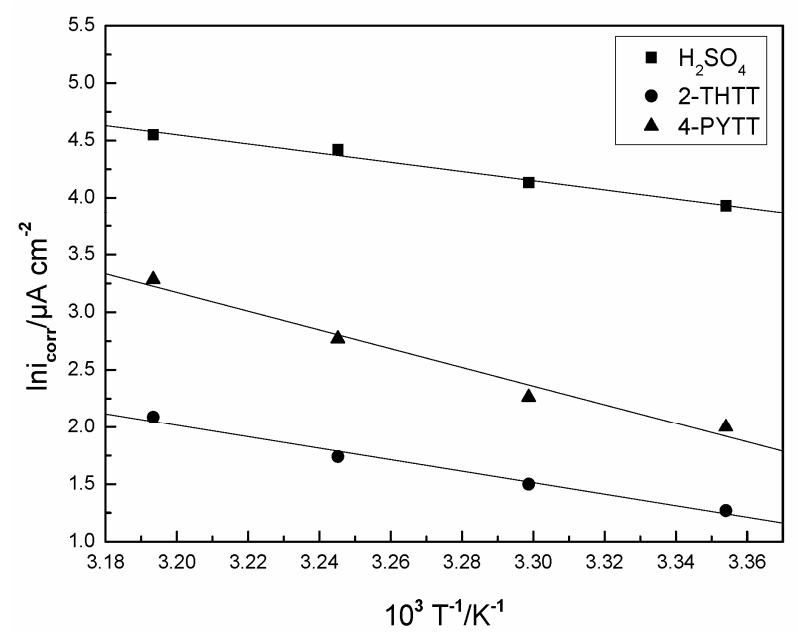

Figure 4. Arrhenius plots for copper in $0.5 \mathrm{M} \mathrm{H}_{2} \mathrm{SO}_{4}$ and $0.5 \mathrm{M} \mathrm{H}_{2} \mathrm{SO}_{4}+0.1 \mathrm{mM}$ inhibitors.

EIS at $30^{\circ} \mathrm{C}$ after $1 \mathrm{~h}$ of immersion. Nyquist plots of copper in the absence and presence of the tetrazole compounds are presented in Figure 5. Obviously, the presence of the tetrazoles leads to changes of the impedance diagrams both in shape and size. A depressed high-frequency capacitive loop, followed by an obvious lowfrequency diffusion behavior which indicates the diffusion of $\mathrm{O}_{2}$, is observed in Figure 5 in the blank solution; otherwise, the depressed capacitive loop seems to be coupled with low-frequency diffusion behavior in Figure 5. By comparing the Nyquist spectra obtained in the presence or absence of the tetrazoles, it is found that the Warburg impedance disappeared in the solution containing 2-THTT. However, the Warburg impedance still existed in the solution containing 4-PYTT.

The cathodic reaction that occurs on the copper surface in $0.5 \mathrm{M} \mathrm{H}_{2} \mathrm{SO}_{4}$ is the oxygen reduction, since $\mathrm{Cu}$ is nobler than $\mathrm{H}^{+}$in the electromotive series, a cathodic reaction other than the displacement of $\mathrm{H}^{+}$can account for metal dissolution. In addition, the appearance of the Waburg impedance is due to the diffusion of oxygen followed by its reduction reaction in aerated $0.5 \mathrm{M} \mathrm{H}_{2} \mathrm{SO}_{4}$. This is readily available in terms of $\mathrm{O}_{2}$ reduction from solution [44],

$$
\mathrm{O}_{2}+4 \mathrm{H}^{+}+4 \mathrm{e}^{-}=2 \mathrm{H}_{2} \mathrm{O}
$$

While, the anodic reaction occurs through the dissolution of copper on two steps as follows [45],

$$
\begin{aligned}
\mathrm{Cu} & \rightarrow \mathrm{Cu}^{+}+\mathrm{e}^{-} \text {(fast) } \\
\mathrm{Cu}^{+} & \rightarrow \mathrm{Cu}^{2+}+\mathrm{e}^{-} \text {(slow) }
\end{aligned}
$$

From Figure 5, it may be indicated that the corrosion of the copper in the presence of 2-THTT is mainly con-
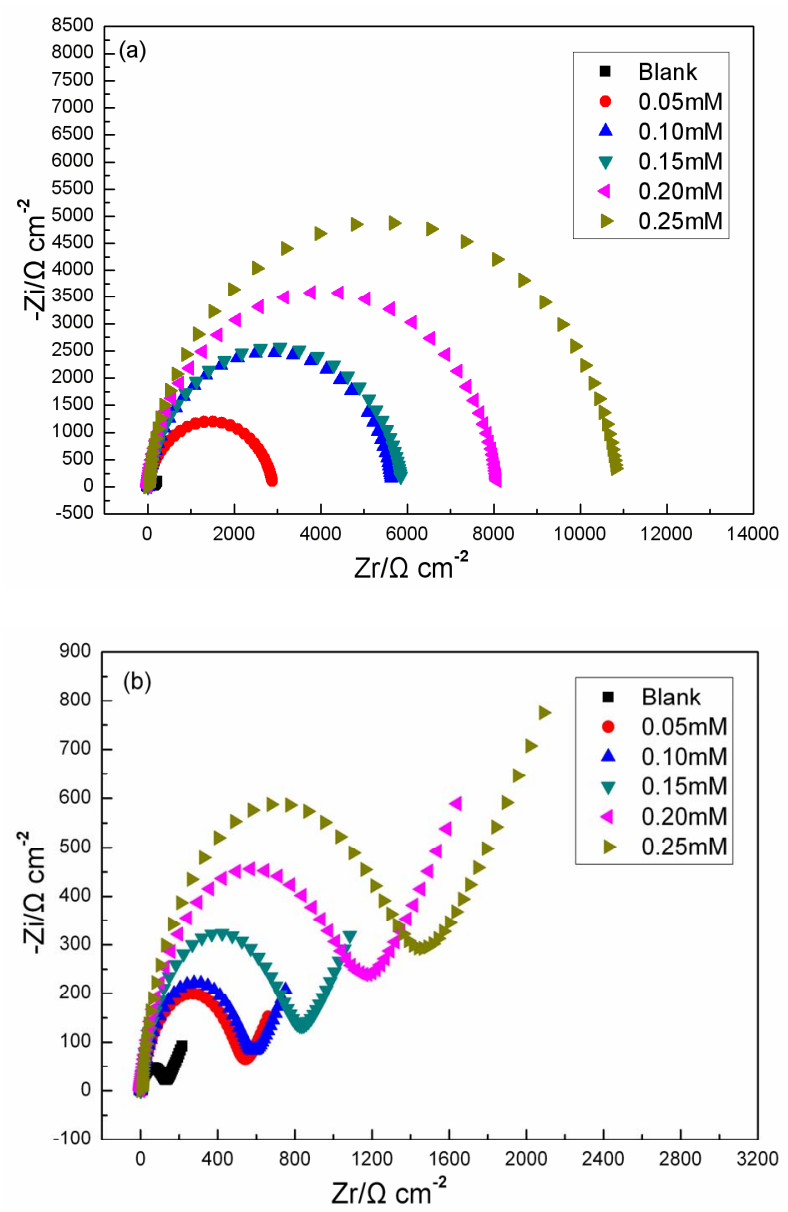

Figure 5. Nyquist diagrams for copper in $0.5 \mathrm{M} \mathrm{H2SO} 4$ in the absence and presence of (a) 2-THTT and (b) 4-PYTT.

trolled by a charge transfer process $[46,47]$. The presence of 2-THTT inhibits significantly the diffusion of $\mathrm{O}_{2}$ from bulk solution to the interface of copper/solution. In addition, from the Nyquist spectra it can be concluded that the corrosion of the copper in the blank solution and in the solution containing 4-PYTT are mixed control processes by activation and diffusion. And the addition of 4-PYTT don't effectively prevent the diffusion of $\mathrm{O}_{2}$ from bulk solution to the interface of copper/solution. This may be one interpretation that 2-THTT has a higher inhibition efficiency than 4-PYTT.

The impedance spectrum displays a high frequency capacitive loop and the Warburg impedance in the low frequency can be analyzed with the equivalent circuit in Figure 6(a) [48], in which $R_{t}$ represents the charge transfer resistance, $W$ the Warburg impedance and $R_{s}$ the solution resistance. A constant phase element (CPE) is substituted for the capacitive element to give a more accurate fit [49], as most capacitive loops are depressed semi-circles rather than regular semi-circles. The imped- 


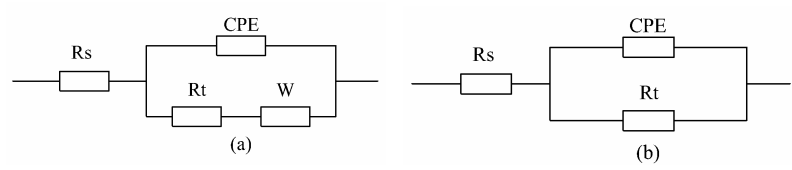

Figure 6. (a) The equivalent circuit to fit the EIS for copper displaying a Warburg impedance; (b) the equivalent circuit to fit the EIS for copper displaying one capacitive loop.

ance spectra displaying one capacitive loop may be analyzed with the electrical circuit in Figure 6(b) [48]. The physical meaning of $R_{s}, R_{t}$ and $C P E$ is the same with what they express in Figure 6(a).

The $C P E$ is a special element whose impedance value is a function of the angular frequency, $\omega$, and whose phase is independent of the frequency. The impedance of a constant phase element is described by the expression:

$$
Z_{C P E}=Y_{0}^{-1}(j \omega)^{-n}
$$

where $Y_{0}$ is a proportional factor, $\omega$ the angular frequency and $\mathrm{n}$ the meaning of a phase shift. For $n=0, C P E$ represents a resistance, for $n=1$ a capacitance, for $n=$ 0.5 a Warburg element and for $n=-1$ an inductance. According to C.H. Hsu, F and Mansfeld [50], the values of the double-layer capacitance $\left(C_{d l}\right)$ can be obtained from the equation:

$$
C_{d l}=Y_{0}\left(\omega_{m}^{\prime \prime}\right)^{n-1}
$$

where $\omega_{m}^{\prime \prime}$ is the angular frequency at which the imaginary part of the impedance has a maximum.

Charge transfer resistance values $\left(R_{t}\right)$ and double layer capacitance values $\left(C_{d l}\right)$ were obtained and shown in Table 3 . The inhibition efficiency $(E \%)$ was calculated by the charge transfer resistance as follows:

$$
E(\%)=\frac{R_{t}-R_{t}^{0}}{R_{t}} \times 100
$$

where $R_{t}^{0}$ and $R_{t}$ are the charge transfer resistance values without and with inhibitor, respectively. The same trend about inhibition efficiencies was obtained from the two methods, Polarization curves and EIS results. The different values of inhibition efficiency were obtained from two methods and it may be attributed to the different surface status of the electrode in two measurements [42]. EIS measurements were performed at the rest potential, while in polarization measurements the electrode potential was polarized to high overpotential, non-uniform current distributions, solution conductivity, counter and reference electrode placement, etc., all this will lead to the difference between the electrode area actually undergoing polarization and the total area [51].

As it can be seen from Table 3, the $C_{d l}$ tends to decrease with the increase of the concentration. $R_{t}$ tends to increase with the increase of the concentration. Compared with 4-PYTT, the more pronounced effect and higher charge transfer resistance have been found in the case of 2-THTT. This phenomenon may indicate that, for 5 -substituted tetrazoles compounds, the inhibition ability depends on the position of the heteroatom and the types of the heterocycle on the substituent.

The decrease in the $C_{d l}$, which can result from the decrease in local dielectric constant and/or the increase in the thickness of the electrical double layer, suggests that the tetrazoles molecules take the place of water mole-

\begin{tabular}{|c|c|c|c|c|c|c|}
\hline Inhibitor & $C_{i n h}(\mathrm{mM})$ & $R_{s}\left(\Omega \mathrm{cm}^{2}\right)$ & $R_{t}\left(\Omega \mathrm{cm}^{2}\right)$ & $C_{d l}\left(\mu \mathrm{F} \cdot \mathrm{cm}^{-2}\right)$ & $W\left(\mathrm{~m} \Omega \cdot \mathrm{cm}^{2}\right)$ & $E(\%)$ \\
\hline \multirow[t]{3}{*}{ Blank } & - & 0.84 & 123.3 & 133.70 & 28.14 & - \\
\hline & 0.05 & 0.80 & 2905 & 25.59 & - & 95.8 \\
\hline & 0.10 & 0.77 & 5658 & 15.00 & - & 97.8 \\
\hline \multirow[t]{5}{*}{ 2-ТHTT } & 0.15 & 0.82 & 5873 & 14.41 & - & 97.9 \\
\hline & 0.20 & 0.75 & 8091 & 9.52 & - & 98.5 \\
\hline & 0.25 & 0.73 & 10860 & 7.49 & - & 98.9 \\
\hline & 0.05 & 0.71 & 516.1 & 67.45 & 17.49 & 76.1 \\
\hline & 0.10 & 0.80 & 544.9 & 67.23 & 12.08 & 77.4 \\
\hline \multirow[t]{3}{*}{ 4-PYTT } & 0.15 & 0.82 & 774.5 & 61.80 & 8.01 & 84.1 \\
\hline & 0.20 & 0.82 & 1084 & 55.24 & 4.54 & 88.6 \\
\hline & 0.25 & 0.83 & 1318 & 40.08 & 3.11 & 90.6 \\
\hline
\end{tabular}
cules, and then function by adsorption at the metal/solu-

Table 3. Parameters of fitted the EIS for copper in $0.5 \mathrm{M} \mathrm{H}_{2} \mathrm{SO}_{4}$ containing different concentrations of inhibitors at $30^{\circ} \mathrm{C}$. 
tion interface [52].

\subsection{Adsorption Isotherms}

Basic information on the interaction between the inhibittor and the metal surface can be provided by the adsorption isotherm, which depends on the degree of electrode surface coverage $(\theta)$. The EIS data were used to evaluate the surface coverage values as follows:

$$
\theta=\frac{C_{d l(\theta=0)}-C_{d l, \theta}}{C_{d l(\theta=0)}-C_{d l(\theta=1)}}
$$

where $C_{d l(\theta=0)}$ and $C_{d l(\theta=1)}$ are the double layer capacitances of the inhibitor-free and entirely inhibitor-covered surfaces, respectively, $C_{d l, \theta}$ is the composite total double layer capacitance for any intermediate coverage $(\theta)$. Because of the small permittivity of organic compound, $C_{d l(\theta=1)}$ approximates to zero. The surface coverage values $(\theta)$ were tested graphically to allow fitting of a suitable adsorption isotherm including Langmuir, Fumkin, Temkin, etc. The plots of $C_{i n h} / \theta$ against $C_{i n h}$ for 2-THTT and 4-PYTT give straight lines with almost unit slope (Figure 7 and Table 4). The correlation coefficients of 2-THTT and 4-PYTT are 0.9997 and 0.9666, correspondingly. It is to say that their correlation coefficients are both greater than 0.95 . This indicates that the tetrazole compounds obey the Langmuir adsorption isotherm on the copper in $0.5 \mathrm{M} \mathrm{H}_{2} \mathrm{SO}_{4}$ :

$$
\theta=\frac{K C_{i n h}}{1+K C_{i n h}}
$$

where $K$ is the equilibrium constant of the adsorption process. The free energy of adsorption $\Delta G_{a d s}$ can be calculated from the equation:

$$
K=\frac{1}{55.5} \exp \left(\frac{-\Delta G_{a d s}}{R T}\right)
$$

As it can be seen from Table 3, the negative $\Delta G_{a d s}$ values of the tetrazole compounds are obtained, indicating that the adsorption process takes place spontaneously. It is well known that values of $-\Delta G_{a d s}$ of the order of $20 \mathrm{~kJ} \cdot \mathrm{mol}^{-1}$ or lower indicate a physisorption mechanism; those of the order of $40 \mathrm{~kJ} \cdot \mathrm{mol}^{-1}$ or higher involve charge sharing or a transfer from the inhibitor molecules to the metal surface to form a co-ordinate type of bond [53].
The $\Delta G_{a d s}$ values of 2-THTT and 4-PYTT are -38.7 $\mathrm{kJ} \cdot \mathrm{mol}^{-1}$ and $-34.5 \mathrm{~kJ} \cdot \mathrm{mol}^{-1}$ respectively. This indicates that the adsorption mechanism of 2-THTT and 4-PYTT on copper in $0.5 \mathrm{M} \mathrm{H}_{2} \mathrm{SO}_{4}$ is not typical chemisorption. Combined with the analysis to polarization curves, it may be concluded that the adsorption of 2-THTT and 4-PYTT is a combination of physisorption and chemisorption.

\subsection{Quantum Chemical Calculation}

In order to study the effect of molecular structure on the inhibition efficiency, quantum chemical calculations were performed to use semi-empirical PM3 method. The optimized geometry of molecules is shown in Figure 8. The computed quantum chemical properties such as energy of highest occupied molecular orbital $\left(E_{\text {НОмо }}\right)$, energy of lowest unoccupied molecular orbital $\left(E_{L U M O}\right)$, the energy band gap $(\Delta E)$ and dipole moment $(\mu)$ are summarized in the Table 5 .

$E_{\text {НОмо }}$ often indicates the electron donating ability of the molecule and the inhibition efficiency increases with the increasing $E_{\text {НОмо }}$ values. High $E_{\text {НОмо }}$ values indicate that the molecule has a tendency to donate electrons to appropriate acceptor molecules with low energy empty molecular orbitals. The increasing values of the $E_{\text {Номо }}$ facilitate adsorption by influencing on the transport process through the adsorbed layer [54]. $E_{\text {LUMO }}$ indicates the ability of the molecules to accept electrons. The lower value of $E_{L U M O}$, the more probable the molecule accepts

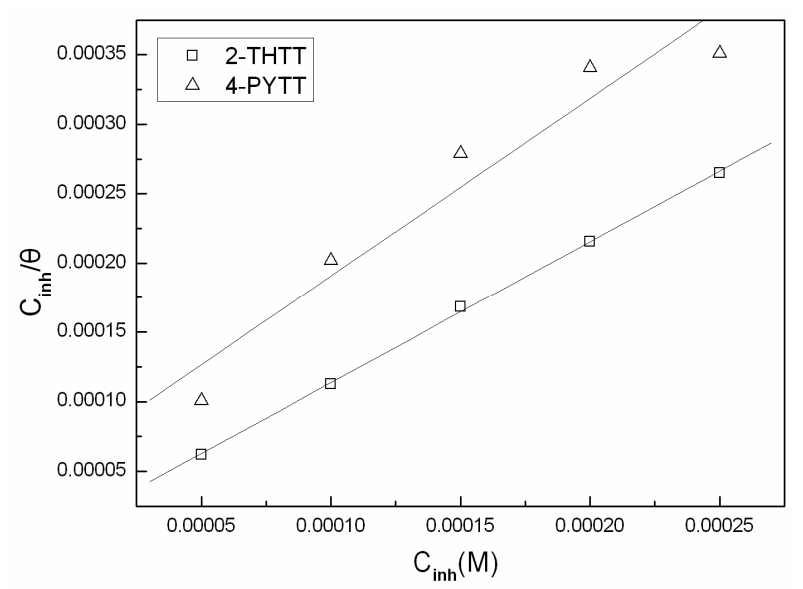

Figure 7. Langmuir adsorption plots of the inhibitors on copper in $0.5 \mathrm{M} \mathrm{H}_{2} \mathrm{SO}_{4}$.

Table 4. The results of Langmuir isotherm for the inhibitors.

\begin{tabular}{cccc}
\hline Inhibitors & Fitting equations & Correlation coefficient & $\Delta G_{a d s}\left(\mathrm{~kJ} \cdot \mathrm{mol}^{-1}\right)$ \\
\hline 2-THTT & $C_{\text {inh }} / \theta=1.19 \times 10^{-5}+1.02 C_{\text {inh }}$ & 0.9997 & -38.7 \\
4-PYTT & $C_{\text {inh }} / \theta=6.27 \times 10^{-5}+1.28 C_{\text {inh }}$ & 0.9666 & -34.5 \\
\hline
\end{tabular}




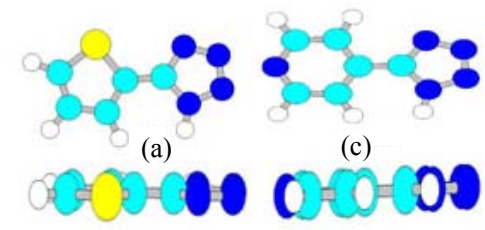

(b)

(d)

Figure 8. Optimized structures of the tetrazoles (a) is vertical view of 2-THTT and (b) is plan view of 2-THTT; (c) is vertical view of 4-PYTT and (d) is plan view of 4-PYTT).

Table 5. Calculated quantum chemical parameters of the tetrazole compounds.

\begin{tabular}{ccccc}
\hline compounds & $E_{\text {номо }}(\mathrm{eV})$ & $E_{L U M O}(\mathrm{eV})$ & $\Delta E(\mathrm{eV})$ & $\mu($ Debye $)$ \\
\hline 2-ТНTT & -9.89 & -1.47 & 8.42 & 6.21 \\
4-PYTT & -10.42 & -1.41 & 9.01 & 4.24 \\
\hline
\end{tabular}

electrons [7]. The energy gap between $L U M O$ and HOMO $\left(\triangle E=E_{\text {LUMO }}-E_{\text {HOMO }}\right)$ is a parameter that the smaller value causes higher inhibition efficiencies of the molecule $[7,55]$. For the dipole moment $(\mu)$, highervalues will favorite enhancement of corrosion inhibition [52]. It is reported that excellent corrosion inhibitors are usually those organic compounds which not only offer electrons to the unoccupied $d$ orbital of the metal, but also accept free electrons from the metal into anti-bonding orbital to form a feedback bond [56,57].

It is clear from Figure 8 that both of the two tetrazoles studied are planar structures. The planar structure can provide a larger coverage area and so it can contribute to the adsorption of tetrazole on copper surface.

It is clear from Table 5 that 2-THTT has the higher values of $E_{\text {HOMO }}, \mu$ and the lower values of $E_{L U M O}, \Delta E$ than 4-PYTT. These Quantum chemical parameters indicate that 2-THTT has higher inhibition efficiency than 4-PYTT. The result is consistent with the discussion in Subsection 3.1 and 3.3. The inhibition efficiency is associated with the changes of the $E_{\text {HOMO }}$ and $E_{L U M O}$, which suggests that 2-THTT is perhaps the better acceptor of the electron as well as the better donor of the electron than 4-PYTT. Due to the stronger electron-withdrawing effect of thienyl than pyridyl, the dipole moments of 2-THTT is higher than that of 4-PYTT. And because of that, a correlation between the dipole moments of the molecules and inhibition efficiencies is observed. The energy gap between $L U M O$ and HOMO $(\triangle E)$ is alsofound to correlate well with inhibition efficiencies of inhibitors. Thus we can conclude that energy of highest occupied molecular orbital ( $E_{\text {Номо }}$ ), energy of lowest unoccupied molecular orbital $\left(E_{L U M O}\right)$, the energy band gap $(\Delta E)$ and dipole moment $(\mu)$ are found to correlate well with experimental inhibition efficiencies of inhibittors.

\section{Conclusions}

The following conclusions can be drawn from this study.

1) Both of the two 5-substituted tetrazoles show efficient inhibition properties for the corrosion of copper in 0.5 aerated $\mathrm{M} \mathrm{H}_{2} \mathrm{SO}_{4}$ solution, but 2-THTT shows better performance. The inhibition efficiency increases with the increasing concentration of the inhibitors and inhibition efficiency of 2-THTT reaches $93.1 \%$ at $0.25 \mathrm{mM}$.

2) Polarization curves measurements show that both the two 5-substituted tetrazoles are mixed-type inhibitors.

3) Results of EIS suggest that the corrosion of the copper in the presence of 2-THTT is mainly controlled by a charge transfer process. The corrosion of the copper in the blank solution and in the solution containing 4-PYTT is a mixed control process by activation and diffusion. In addition, the appearance of the Waburg impedance is due to the diffusion of oxygen followed by its reduction reaction.

4) The adsorption of 5-substituted tetrazoles on the copper/solution interface obeys the Langmuir adsorption isotherm model. The negative $\Delta G_{a d s}$ values indicate that the adsorption of 5-substituted tetrazoles on the copper surface in aerated $0.5 \mathrm{M} \mathrm{H}_{2} \mathrm{SO}_{4}$ solution is spontaneous.

5) The quantum chemical calculations show that energy of highest occupied molecular orbital $\left(E_{\text {НОмо }}\right)$, energy of lowest unoccupied molecular orbital $\left(E_{L U M O}\right)$, the energy band gap $(\Delta E)$ and dipole moment $(\mu)$ are found to correlate well with experimental inhibition efficiencies of inhibitors.

\section{Acknowledgements}

This work is supported by the Open Fund of the State Key Laboratory of Materials-Oriented Chemical Engineering (KL09-9), the postgraduate practice innovation fund of Jiangsu province, and the doctor thesis innovation fund of Nanjing University of Technology.

\section{REFERENCES}

[1] G. K. Gomma, "Effect of Azole Compounds on Corrosion of Copper in Acid Medium," Materials Chemistry and Physics, Vol. 56, No. 1, September 1998, pp. 27-34. doi:10.1016/S0254-0584(98)00086-8

[2] M. A. Elmorsi and A. M. Hassanien, "Corrosion Inhibition of Copper by Heterocyclic Compounds," Corrosion Science, Vol. 41, No. 12, December 1999, pp. 2337-2352. doi:10.1016/S0010-938X(99)00061-X

[3] J. M. Bastidas, P. Pinilla, E. Cano, J. L. Polo and S. Miguel, "Copper Corrosion Inhibition by Triphenylmethane 
Derivatives in Sulphuric Acid Media," Corrosion Science, Vol. 45, No. 2, February 2003, pp. 427-449. doi:10.1016/S0010-938X(02)00123-3

[4] S. A. Abd El-Maksoud, "The Effect of Hexadecyl Pyridinium Bromide and Hexadecyl Trimethyl Ammonium Bromide on the Behaviour of Iron and Copper in Acidic Solutions," Journal of Electroanalytical Chemistry, Vol. 565, No. 2, April 2004, pp. 321-328. doi:10.1016/j.jelechem.2003.10.026

[5] A. G. Christy, A. Lowe, V. Otieno-Alego, M. Stoll and R. D. Webster, "Voltammetric and Raman Microspectroscopic Studies on Artificial Copper Pits Grown in Simulated Potable Water," Journal of Applied Electrochemistry, Vol. 34, No. 2, 2004, pp. 225-233. doi:10.1023/B:JACH.0000009923.35223.f8

[6] E. M. Sherif, R. M. Erasmus and J. D. Comins, "Corrosion of Copper in Aerated Acidic Pickling Solutions and Its Inhibition by 3-Amino-1,2,4-Triazole-5-Thiol," Journal of Colloid and Interface Science, Vol. 306, No. 1, February 2007, pp. 96-104.

doi:10.1016/j.jcis.2006.10.029

[7] Y. M. Tang, W. Z. Yang, X. S. Yin, Y. Liu, R. Wan and J. T. Wang, "Phenyl-Substituted Amino Thiadiazoles as Corrosion Inhibitors for Copper in $0.5 \mathrm{M} \mathrm{H}_{2} \mathrm{SO}_{4}$," Materials Chemistry and Physics, Vol. 116, No. 2-3, August 2009, pp. 479-483.

[8] S. Kertit, H. Es-Soufi, B. Hammouti and M. Benkaddour, "1-Phenyl-5-Mercapto-1,2,3,4-Tetrazole (PMT): Un Nouvel Inhibiteur de Corrosion de L'alliage $\mathrm{Cu}-\mathrm{Zn}$ Efficace à Tres Faible Concentration," Journal de Chimie Physique et de Physico-Chimie Biologique, Vol. 95, No. 9, 1998, pp. 2070-2082.

[9] X. R. Ye, X. Q. Xin, J. J. Zhu and Z. L. Xue, "Coordination Compound Films of 1-Phenyl-5-Mercapto Tetrazole on Copper Surface," Applied Surface Science, Vol. 135, No. 1-4, 1998, pp. 307-317. doi:10.1016/S0169-4332(98)00301-8

[10] M. Mihit, S. El Issami, M. Bouklah, L. Bazzi, B. Hammouti, E. Ait Addi, R. Salghi and S. Kertit, "The Inhibited Effect of Some Tetrazolic Compounds towards the Corrosion of Brass in Nitric Acid Solution," Applied Surface Science, Vol. 252, No. 6, 2006, pp. 2389-2395. doi:10.1016/j.apsusc.2005.04.009

[11] E. Szőcs, Gy. Vastag, A. Shaban and E. Kálmán, “Electrochemical Behaviour of an Inhibitor Film Formed on Copper Surface," Corrosion Science, Vol. 47, No. 4, 2005, pp. 893-908.

[12] J. Telegdi, A. Shaban and E. Kálmán, "EQCM Study of Copper and Iron Corrosion Inhibition in Presence of Organic Inhibitors and Biocides," Electrochimica Acta, Vol. 45, No. 22-23, 2000, pp. 3639-3647. doi:10.1016/S0013-4686(00)00447-3

[13] M. Mihit, R. Salghi, S. El Issami, L. Bazzi, B. Hammouti, El. Ait Addi and S. Kertit, "A Study of Tetrazoles Derivatives as Corrosion Inhibitors of Copper in Nitric Acid," Pigment \& Resin Technology, Vol. 35, No. 3,
2006, pp. 151-157.

[14] E.-S. M. Sherif, R. M. Erasmus and J. D. Comins, "Inhibition of Copper Corrosion in Acidic Chloride Pickling Solutions by 5-(3-Aminophenyl)-Tetrazole as a Corrosion Inhibitor," Corrosion Science, Vol. 50, No. 12, 2008, pp. 3439-3445. doi:10.1016/i.corsci.2008.10.002

[15] T. Arslan, F. Kandemirli, E. E. Ebenso, I. Love and H. Alemu, "Quantum Chemical Studies on the Corrosion Inhibition of Some Sulphonamides on Mild Steel in Acidic Medium," Corrosion Science, Vol. 51, No. 1, January 2009, pp. 35-47. doi:10.1016/j.corsci.2008.10.016

[16] M. J. Bahrami, S. M. A. Hosseini and P. Pilvar, "Experimental and Theoretical Investigation of Organic Compounds as Inhibitors for Mild Steel Corrosion in Sulfuric Acid Medium," Corrosion Science, Vol. 52, No. 9, September 2010, pp. 2793-2803.

[17] F. Kandemirli and S. Sagdinc, "Theoretical Study of Corrosion Inhibition of Amides and Thiosemicarbazones," Corrosion Science, Vol. 49, No. 5, May 2007, pp. 2118-2130. doi:10.1016/i.corsci.2006.10.026

[18] D. Wang, S. Li, Y. Ying, M. Wang, H. Xiao and Z. Chen, "Theoretical and Experimental Studies of Structure and Inhibition Efficiency of Imidazoline Derivatives," Corrosion Science, Vol. 41, No. 10, October 1999, pp. 19111919. doi:10.1016/S0010-938X(99)00027-X

[19] G. Bereket, C. Ogretir and A. Yurt, "Quantum Mechanical Calculations on Some 4-Methyl-5-Substituted Imidazole Derivatives as Acidic Corrosion Inhibitor for Zinc," Journal of Molecular Structure: THEOCHEM, Vol. 571, No. 1-3, August 2001, pp. 139-145. doi:10.1016/S0166-1280(01)00552-8

[20] N. Khalil, "Quantum Chemical Approach of Corrosion Inhibition," Electrochimica Acta, Vol. 48, No. 18, August 2003, pp. 2635-2640. doi:10.1016/S0013-4686(03)00307-4

[21] J. Zhang, J. Liu, W. Yu, Y. Yan, L. You and L. Liu, "Molecular Modeling of the Inhibition Mechanism of 1-(2-Aminoethyl)-2-Alkyl-Imidazoline," Corrosion Science, Vol. 52, No. 6, June 2010, pp. 2059-2065. doi:10.1016/j.corsci.2010.02.018

[22] M. Lebrini, F. Bentiss, H. Vezin and M. Lagrenée, "The Inhibition of Mild Steel Corrosion in Acidic Solutions by 2,5-Bis(4-Pyridyl)-1,3,4-Thiadiazole: Structure-Activity Correlation," Corrosion Science, Vol. 48, No. 5, May 2006, pp. 1279-1291. doi:10.1016/i.corsci.2005.05.001

[23] H. Ashassi-Sorkhabi, B. Shaabani and D. Seifzadeh, "Effect of Some Pyrimidinic Shciff Bases on the Corrosion of Mild Steel in Hydrochloric Acid Solution," Electrochimica Acta, Vol. 50, No. 16-17, May 2005, pp. 34463452 .

[24] J. J. Shie and J. M. Fang, "Direct Conversion of Aldehydes to Amides, Tetrazoles, and Triazines in Aqueous Media by One-Pot Tandem Reactions," Journal of Organic Chemistry, Vol. 68, No. 3, 2003, pp. 1158-1160. doi:10.1021/jo026407z 
[25] B. El Mehdi, B. Mernari, M. Traisnel, F. Bentiss and M. Lagrenée, "Synthesis and Comparative Study of the Inhibitive Effect of Some New Triazole Derivatives towards Corrosion of Mild Steel in Hydrochloric Acid Solution," Materials Chemistry and Physics, Vol. 77, No. 2, January 2003, pp. 489-496. doi:10.1016/S0254-0584(02)00085-8

[26] O. L. Riggs Jr., "Corrosion Inhibitors (2nd Edition)," C. C. Nathan, Houston, 1973.

[27] E. S. Ferreira, C. Giancomelli, F. C. Giacomelli and A. Spinelli, "Evaluation of the Inhibitor Effect of L-Ascorbic Acid on the Corrosion of Mild Steel," Materials Chemistry and Physics, Vol. 83, No. 1, 2004, pp. 129-134. doi:10.1016/i.matchemphys.2003.09.020

[28] G. Lyberatos and L. Kobotiatis, "Inhibition of Aluminum 7075 Alloy Corrosion by the Concerted Action of Nitrate and Oxalate Salts," Corrosion, Vol. 47, No. 11, 1991, pp. 820-824.

[29] S. Magaino, "Corrosion Rate of Copper Rotating-DiskElectrode in Simulated Acid Rain," Electrochimica Acta, Vol. 42, No. 3, 1997, pp. 377-382. doi:10.1016/S0013-4686(96)00225-3

[30] Y. Lu, W. Wang, H. Xu, X. Kong and J. Wang, "Copper Corrosion and Anodic Electrodissolution Mechanisms in Naturally Aerated Stagnant $0.5 \mathrm{M} \mathrm{H}_{2} \mathrm{SO}_{4}$, " Corrosion Science, Vol. 52, No. 3, 2010, pp. 780-787. doi:10.1016/i.corsci.2009.10.037

[31] F. Bensajjay, S. Alehyen, M. El Achouri and S. Kertit, "Corrosion Inhibition of Steel by 1-Phenyl 5-Mercapto 1,2,3,4-Tetrazole in Acidic Environments (0.5 $\mathrm{M} \mathrm{H}_{2} \mathrm{SO}_{4}$ and $\left.1 / 3 \mathrm{M} \mathrm{H}_{3} \mathrm{PO}_{4}\right)$," Anti-Corrosion Methods and Materials, Vol. 50, No. 6, 2003, pp. 402-409.

[32] M. S. Morad and A. M. Kamal El-Dean, "2,2'-Dithiobis (3-Cyano-4,6-Dimethylpyridine): A New Class of Acid Corrosion Inhibitors for Mild Steel," Corrosion Science, Vol. 48, No. 11, 2006, pp. 3398-3412. doi:10.1016/j.corsci.2005.12.006

[33] A. Zarrouk, I. Warad, B. Hammouti, A. Dafali, S. S. Al-Deyab and N. Benchat, "The Effect of Temperature on the Corrosion of $\mathrm{Cu} / \mathrm{HNO}_{3}$ in the Presence of Organic Inhibitor: Part-2," International Journal of Electrochemical Science, Vol. 5, No. 10, 2010, pp. 1516-1526.

[34] S. Aloui, I. Forsal, M. Sfaira, M. Ebn Touhami, M. Taleb, M. Filali Baba and M. Daoudi, "New Mechanism Synthesis of 1,4-Benzothiazine and Its Inhibition Performance on Mild Steel in Hydrochloric Acid," Portugaliae Electrochimica Acta, Vol. 27, No. 5, 2009, pp. 599-613. doi:10.4152/pea.200905599

[35] M. Behpour, S. M. Ghoreishi, A. Gandomi-Niasar, N. Soltani and M. Salavati-Niasari, "The Inhibition of Mild Steel Corrosion in Hydrochloric Acid Media by Two Schiff Base Compounds," Journal of Materials Science, Vol. 44, No. 10, 2009, pp. 2444-2453. doi:10.1007/s10853-009-3309-y

[36] E. E. Oguzie, "Adsorption and Corrosion Inhibitive Properties of Azadirachta Indica in Acid Solutions,"
Pigment \& Resin Technology, Vol. 35, No. 6, 2006, pp. 334-340.

[37] S. Martinez and I. Štern, "Inhibitory Mechanism of LowCarbon Steel Corrosion by Mimosa Tannin in Sulphuric Acid Solutions," Journal of Applied Electrochemistry, Vol. 31, No. 9, 2001, pp. 973-978. doi:10.1023/A:1017989510605

[38] M. Behpour, S. M. Ghoreishi, N. Soltani and M. Salavati-Niasari, "The Inhibitive Effect of Some bis-N,S-bidentate Schiff Bases on Corrosion Behaviour of 304 Stainless Steel in Hydrochloric Acid Solution," Corrosion Science, Vol. 51, No. 5, 2009, pp. 1073-1082.

[39] I. Ahamad, R. Prasad and M. A. Quraishi, "Thermodynamic, Electrochemical and Quantum Chemical Investigation of Some Schiff Bases as Corrosion Inhibitors for Mild Steel in Hydrochloric Acid Solutions," Corrosion Science, Vol. 52, No. 3, 2010, pp. 933-942. doi:10.1016/j.corsci.2009.11.016

[40] S. Martinez and I. Stern, "Thermodynamic Characterization of Metal Dissolution and Inhibitor Adsorption Processes in the Low Carbon Steel/Mimosa Tannin/Sulfuric Acid System," Applied Surface Science, Vol. 199, No. 1-4, 2002, pp. 83-89. doi:10.1016/S0169-4332(02)00546-9

[41] T. Szauer and A. Brandt, "Influence of Bromide and Thiourea Additions on the Reduction of Metal Ions from Molten $\mathrm{Ca}\left(\mathrm{NO}_{3}\right)_{2} \cdot 4 \mathrm{H}_{2} \mathrm{O}$ at the Mercury Electrode-I. Complex Formation," Electrochimica Acta, Vol. 26, No. 2, 1981, pp. 203-209. doi:10.1016/0013-4686(81)85004-9

[42] Y. Tang, X. Yang, W. Yang, Y. Chen and R. Wan, "Experimental and Molecular Dynamics Studies on Corrosion Inhibition of Mild Steel by 2-Amino-5-Phenyl-1,3,4Thia-Diazole," Corrosion Science, Vol. 52, No. 1, 2010, pp. 242-249. doi:10.1016/j.corsci.2009.09.010

[43] Y. Abboud, A. Abourriche, T. Saffaj, M. Berrada, M. Charrouf, A. Bennamara and H. Hannache, "A Novel Azo Dye, 8-Quinolinol-5-Azoantipyrine as Corrosion Inhibitor for Mild Steel in Acidic Media," Desalination, Vol. 237, No. 1-3, 2009, pp. 175-189.

[44] A. M. S. El Din, M. E. El Dahshan and A. M. T. El Din, "Dissolution of Copper and Copper-Nickel Alloys in Aerated Dilute $\mathrm{HCl}$ Solutions," Desalination, Vol. 130, No. 1, 2000, pp. 89-97.

[45] E. M. Sherif, R. M. Erasmus and J. D. Comins, "Effects of 3-Amino-1,2,4-Triazole on the Inhibition of Copper Corrosion in Acidic Chloride Solutions," Journal of Colloid and Interface Science, Vol. 311, No. 1, 2007, pp. 144-151. doi:10.1016/j.jcis.2007.02.064

[46] M. El Achouri, S. Kertit, H. M. Gouttaya, B. Nciri, Y. Bensouda, L. Perez, M. R. Infante and K. Elkacemi, "Corrosion Inhibition of Iron in $1 \mathrm{M} \mathrm{HCl}$ by Some Gemini Surfactants in the Series of Alkanediyl- $\alpha, \omega$-Bis-(Dimethyl Tetradecyl Ammonium Bromide)," Progress in Organic Coatings, Vol. 43, No. 4, 2001, pp. 267-273. doi:10.1016/S0300-9440(01)00208-9

[47] A. Chetouani, A. Aouniti, B. Hammouti, N. Benchat, T. 
Benhadda and S. Kertit, "Corrosion Inhibitors for Iron in Hydrochloride Acid Solution by Newly Synthesised Pyridazine Derivatives," Corrosion Science, Vol. 45, No. 8, 2003, pp. 1675-1684.

doi:10.1016/S0010-938X(03)00018-0

[48] S. Li, S. Chen, S. Lei, H. Ma, R. Yu and D. Liu, "Investigation on Some Schiff Bases as $\mathrm{HCl}$ Corrosioninhibitors for Copper," Corrosion Science, Vol. 41, No. 7, 1999, pp. 1273-1287. doi:10.1016/S0010-938X(98)00183-8

[49] X. Wu, H. Ma, S. Chen, Z. Xu and A. Sui, "General Equivalent Circuts for Faradic Electrode Processes under Electrochemical Reaction Control," Journal of The Electrochemical Society, Vol. 146, No. 5, May 1999, pp. 18471853. doi:10.1149/1.1391854

[50] C. H. Hsu and F. Mansfeld, "Technical Note: Concerning the Conversion of the Constant Phase Element Parameter $\mathrm{Y}_{0}$ into a Capacitance," Corrosion, Vol. 57, No. 9, 2001, pp. 747-748.

[51] R. G. Kelly, J. R. Scully, D. W. Shoesmith and R. G. Buchheit, "Electrochemical Techniques in Corrosion Science and Engineering," Marcel Dekker Inc., New York, 2002.

[52] M. Lebrini, M. Lagrenee, M. Traisnel, L. Gengembre, H. Vezin and F. Bentiss, "Enhanced Corrosion Resistance of Mild Steel in Normal Sulfuric Acid Medium by 2,5-Bis (n-Thienyl)-1,3,4-Thiadiazoles: Electrochemical, X-Ray Photoelectron Spectroscopy and Theoretical Studies," Applied Surface Science, Vol. 253, No. 23, 2007, pp.
9267-9276. doi:10.1016/j.apsusc.2007.05.062

[53] F. M. Donahue and K. Nobe, "Theory of Organic Corrosion Inhibitors," Journal of the Electrochemical Society, Vol. 112, No. 9, 1965, pp. 886-891. doi:10.1149/1.2423723

[54] M. Behpour, S. M. Ghoreishi, N. Soltani, M. SalavatiNiasari, M. Hamadanian and A. Gandomi, "Electrochemical and Theoretical Investigation on the Corrosion Inhibition of Mild Steel by Thiosalicylaldehyde Derivatives in Hydrochloric Acid Solution," Corrosion Science, Vol. 50, No. 8, 2008, pp. 2172-2181. doi:10.1016/j.corsci.2008.06.020

[55] D. Q. Zhang, Z. X. An, Q. Y. Pan, L. X. Gao and G. D. Zhou, "Comparative Study of Bis-Piperidiniummethyl Urea and Mono-Piperidiniummethyl-Urea as Volatile Corrosion Inhibitors for Mild Steel," Corrosion Science, Vol. 48, No. 6, 2006, pp. 1437-1448. doi:10.1016/j.corsci.2005.06.007

[56] I. Ahamad, R. Prasad and M. A. Quraishi, “Adsorption and Inhibitive Properties of Some New Mannich Bases of Isatin Derivatives on Corrosion of Mild Steel in Acidic Media," Corrosion Science, Vol. 52, No. 4, 2010, pp. 1472-1481. doi:10.1016/j.corsci.2010.01.015

[57] P. Zhao, Q. Liang and Y. Li, "Electrochemical, SEM/ EDS and Quantum Chemical Study of Phthalocyanines as Corrosion Inhibitors for Mild Steel in $1 \mathrm{~mol} / \mathrm{HCl}$," Applied Surface Science, Vol. 252, No.5, 2005, pp. 15961607. doi:10.1016/j.apsusc.2005.02.121 